\title{
Prevalence of sexual dysfunction and related factors among diabetes mellitus patients in Southwest Ethiopia
}

\author{
Adane Asefa ${ }^{1 *} \mathbb{D}$, Tadesse Nigussie ${ }^{1}$, Andualem Henok ${ }^{1}$ and Yitagesu Mamo ${ }^{2}$
}

\begin{abstract}
Background: Diabetes mellitus causes multiple medical, psychological and sexual problems in both men and women. Sexual dysfunction is one of those problems that lead to a strong social and psychological problem which adversely affect marital relation and treatment outcome. The issue has not been well studied in Ethiopia; therefore, this study aimed to evaluate the prevalence and factors related to sexual dysfunction in adult patients with diabetes mellitus.

Methods: Facility-based cross-sectional study was conducted among adults with diabetes mellitus on follow-up at diabetic clinics of Mizan-Tepi University Teaching Hospital and Tepi General Hospital. A consecutive sampling technique was employed to select 423 study participants, and data were collected through interviewer-administered questionnaire and patients' medical chart review. Changes in Sexual Functioning Questionnaire-fourteen items (CSFQ-14) was used to measure sexual dysfunction. Descriptive statistics and binary logistic regression analyses were performed. Two tail tests at a of less 0.05 were used as a level of significance.
\end{abstract}

Results: A total of 398 diabetic patients were interviewed, with a 94\% response rate. The prevalence of sexual dysfunction was 53.3\%. Age of above 41 years (AOR: 3.98, 95\% Cl 2.32-6.85), lack of formal education (AOR: 3.20, 95\% Cl 1.60-6.39), divorced or widowed (AOR: 5.28, 95\% Cl 2.35-11.86), type 2 DM (AOR: 4.52, 95\% Cl 2.17-9.42), depression (AOR: $4.05,95 \% \mathrm{Cl}$ 2.32-7.10), complications or co-morbidity (AOR: 2.05, 95\% Cl 1.18-3.58), and not doing physical activity (AOR: 1.62, 95\% Cl; 1.47-1.77) were significantly associated with sexual dysfunction among diabetes patients.

Conclusions: The prevalence of sexual dysfunction was as high as reports from other studies. Therefore, health care providers should include the issue of sexual health in their routine discussions with adult diabetes mellitus patients. Presence of depression, not doing physical activity and having complications or co-morbidity are modifiable factors associated with sexual dysfunction; therefore, they should be attended during care addressing sexual dysfunction.

Keywords: Diabetes mellitus, Sexual dysfunction, Sexual disorder, Sex disorder

\section{Background}

Diabetes mellitus (DM) is one of the common chronic diseases in the world. About 422 million people were affected in 2014; this figure shows an increasing trend when compared with that of 1980 , which was about 108 million [1]. International Diabetic Association (IDA) report of 2015 estimated that the number of people with diabetes could be increased to 642 million by 2040. The report also shows Ethiopia could be accounted for about

\footnotetext{
* Correspondence: adane779@gmail.com; adaneasefa@mtu.edu.et ${ }^{1}$ Department of Public Health, College of Health Science, Mizan- Tepi University, Mizan-Aman, Ethiopia

Full list of author information is available at the end of the article
}

2,567,900 cases of diabetes [2]. According to World Health Organization (WHO) report, DM caused about 1.5 million deaths in 2012 [1]. Also, diabetes and its complications bring substantial economic loss to people with diabetes and their families, and health systems and national economies through direct medical costs and loss of work and wages [1].

Sexual dysfunction frequently occurs among DM patients [3]. Studies reported the high prevalence, and earlier onset of sexual dysfunction among diabetic men when compared to non-diabetic [3-5]. Similarly, the study conducted in northern Ethiopia showed the prevalence of erectile dysfunction among DM patients was

(c) The Author(s). 2019 Open Access This article is distributed under the terms of the Creative Commons Attribution 4.0 International License (http://creativecommons.org/licenses/by/4.0/), which permits unrestricted use, distribution, and reproduction in any medium, provided you give appropriate credit to the original author(s) and the source, provide a link to the Creative Commons license, and indicate if changes were made. The Creative Commons Public Domain Dedication waiver (http://creativecommons.org/publicdomain/zero/1.0/) applies to the data made available in this article, unless otherwise stated. 
69\% [6]. Also, another study has documented low sexual desire, lack of sexual satisfaction, low vaginal lubrication and orgasmic dysfunction among women with DM [7].

Strong physical, social and psychological problems are associated with sexual dysfunction. For instance, erectile disorder and premature ejaculation are related to anxiety. Moreover, low sexual satisfaction, sadness, low selfesteem, distress, and depression are very common among men who are suffering from sexual dysfunction. In women, arousal, orgasmic and enjoyment problems are associated with anxiety and depression $[8,9]$. Furthermore, sexual dysfunction imposes a challenge to partner relationships. It results in less marital satisfaction, emotional stress, less communication, and difficulty in resolving problems, and finally, it may lead to divorce $[10,11]$. Moreover, patient self-care behavior decreases when there is conflict in marital relationships, and this, in turn, results in poor glycemic control [12].

Few studies were conducted on sexual dysfunction among diabetic patients in Ethiopia, and they focused on erectile dysfunction only $[6,13]$. Moreover, open talk about sexual related issue is a taboo in Ethiopia due to the societal norm. Because of this, most patients do not freely discuss sexual problems with their doctor or partner. As a result, sexual disorder is considered as underrecognized and under-treated disorders in the country. Therefore, this study aimed to evaluate the prevalence and factors related to sexual dysfunction in adult patients with diabetes mellitus.

\section{Methods}

\section{Study design and setting}

A facility-based cross-sectional study was conducted from July 01-31/ 2018 among diabetes mellitus patients on follow-up at diabetic clinics of Mizan Tepi University Teaching Hospital (MTUTH) and Tepi General Hospital (TGH). MTUTH and TGH are located in Southwest Ethiopia at $585 \mathrm{~km}$ and $611 \mathrm{~km}$ from Addis Ababa respectively. MTUTH is found in Mizan-Aman town. The hospital provides service for the population that comes from Bench-Maji, Sheka and Kafa Zones and some parts of Gembella regional state. It has a bed capacity of 209 and has over 400 staff members. TGH located in Tepi town, and it provides service for people who come from Shaka, Kafa and Majang Zones.

\section{Study population and eligibility}

Adult diabetic patients who had been on follow up at diabetic clinics of MTUTH and TGH were a source population. The study population was a sample of adult DM patients who were on follow up during the study period at the diabetic clinics of MTUTH and TGH, and who fulfilled eligibility criteria. Patients who were mentally impaired and unable to give information and/or had sexual disorder before the onset of diabetes mellitus were excluded. Also, females aged above 50 years, and/or those who had history of pelvic surgery were excluded.

\section{Sample size and sampling procedure}

The sample size was determined manually using a single population proportion formula $\left(n=\frac{\left(z_{\alpha / 2}\right)^{2} p(1-p)}{d^{2}}\right)$ [14]; based on the assumptions of $95 \%$ confidence level, 5\% margin of error and a $50 \%$ proportion of sexual dysfunction. The prevalence of $50 \%$ was taken because there was no similar study done in Ethiopia previously. After adding $10 \%$ contingency for non-response, the final sample size for the study was 423 . Based on the total number of patients on follow up at each hospital, the sample size was proportionally allocated to the two study settings. Accordingly, 279 samples were allocated to MTUTH and 144 samples to TGH. The study participants were recruited during their regular medical followup period consecutively based on their arrival at DM clinics of each Hospital.

\section{Data collection tools and procedure}

Changes in Sexual Functioning Questionnaire-fourteen items (CSFQ-14) was adopted and used to measure sexual dysfunction [15]. The questionnaire to assess socio-demographic and behavioral related factors was developed by reviewing different literature. Also, data extraction checklist was prepared to collect data related to medical history. The tool was translated to a local language, "Amharic" then back to English, to ensure its consistency. Then, it was pre-tested on $5 \%$ of the total sample size at Chenna Hospital before the actual data collection to evaluate readability, understandability, completeness, and reliability of the questionnaire, and modified accordingly. Internal consistency for CSFQ-14 was checked and demonstrated Cronbach's alpha of 0.72 and 0.81 for women and men respectively. Finally, the Amharic version was used to collect the data. Trained personnel collected the data through face-to-face interview method. The most recent recorded information related to medical condition were extracted from patient medical chart. Due to the sensitivity of the issue, female data collectors were assigned to collect data from the female participants whereas male data collectors collected data from male participants.

\section{Study variables}

The dependent variable of the study was sexual dysfunction. The independent variables were socio-demographic information (age, sex, religion, marital status, educational status, ethnicity and place of residence), factors related to medical condition (types of DM, duration of treatment, glycemic control, complication or co-morbidity and 
depression) and behavioral factors (physical activity, adherence to antidiabetic medication, alcohol, tobacco and khat use).

\section{Measurements}

Sexual dysfunction was measured using CSFQ-14, a standardized tool used to screen sexual activities. The CSFQ-14 has 14 separate items for males and females to assess sexual function. All items were answered on five Likert scales. The responses were summed up to give a total score of 14-70. The score at or below 47 for males and 41 for females indicates the presence of global sexual dysfunction. The tool also measures five types of sexual dysfunction (pleasure, desire/frequency, desire/ interest, arousal/erection and orgasm/ejaculation). Scores of less than or equal to $6,9,4,3$, and 13 indicate sexual desire/frequency, sexual desire /interest, sexual pleasure, sexual arousal/excitement, and sexual orgasm/ completion dysfunctions respectively in males. In females, scores at or below $6,9,4,12$, and 11 show the presence of sexual desire frequency, sexual desire/interest, sexual pleasure, sexual arousal/excitement, and sexual orgasm/completion dysfunctions respectively.

Glycemic control was assessed using more recent fasting blood sugar (FBS) measurements' of three months. Patients were considered in good glycemic control range if the average FBS level was $\leq 130 \mathrm{mg} / \mathrm{dL}$, and poor glycemic control if it was $>130 \mathrm{mg} / \mathrm{dL}$. Depression symptoms in the past 14 days of the survey were measured using validated patient's health questionnaire-nine (PHQ-9), which is a validated tool [16]. The PHQ- 9 has nine items, each item having 4-point response scales; 'not at all' (0), 'various days' [1], 'more than half of the days' [2] and 'nearly every day' [3]. Summing all these possible, the total score range from 0 to 27 points. The score of 0-4 indicates no or minimal depression, 5-9 is mild depression, 10-14 is moderate depression, 15-19 moderately severe depression and 20-27 severe depression. Overall cutoff $\geq 10$ was used to indicate depression. Data related to complication or comorbidity was obtained from patients' medical charts based on physician diagnosis. If patients had at least one of these conditions; nephropathy, retinopathy, diabetic neuropathy, diabetic foot ulcer, cardiac disease or hypertension they were considered as they had complication or co-morbidity otherwise no. Complication and co-morbidity were merged together because it is very difficult to differentiate them from secondary data if these conditions were occurred secondary to DM or happened as co-morbidity. Duration on antidiabetic treatment was assessed based on patient selfreport of the years elapsed since they started the medication.

Adherence to physical activity was measured based on the participants' responses. Patients who had been regularly engaged in moderate (like slow walking or dancing) to vigorous-intensity exercise (like fast walking or running) at least 2 days per week were classified as adherent to physical activity. We assessed adherence to anti-diabetic medication in the past seven days of survey and respondents were considered adherent if they took all anti-diabetic medication as per the prescription of a physician. The respondents were categorized as substance users if they reported consumption of any of the following substances in any amount in the past 12 months; had drunk common alcohols in the area such as beer, wine or local alcohols like 'Areke', 'Teji'or 'Katikala'; smoked tobacco, chewed 'khat.

\section{Data processing and analysis}

Data were cleaned, coded and entered into Epi data version 3.1 and exported to SPSS version 21 for analysis. Data were explored for unexpected values and outliers and compiled for final analysis. Descriptive statistics such as proportion, mean and standard deviation were computed for categorical and continuous variables as supposed necessary. Bivariate binary logistic regression analyses were done for all independent variables and variables with a $p$-value less than 0.25 were considered as candidates for the multivariable model. Finally, multivariable binary logistic regression analysis was done, and a p-value of $\leq 0.05$ considered as statistically significant. The strength of association was measured using odds ratio at 95\% confidence level. Model fitness was evaluated using the Hosmer-Lemeshow test. In the final model, the extent of multicollinearity was measured using the variance inflation factor (VIF) which was found to be within a tolerable range (less than 10).

\section{Ethical consideration}

Ethical clearance was obtained from the Institutional Review Board (IRB) of Mizan-Tepi University (Ref No: CHS/205/2018). Data were collected after obtaining written informed consent from all respondents. All the information gathered was kept confidential.

\section{Results}

\section{Socio-demographic characteristics}

Among planned 423 planned samples, 398 (94\%) were successfully involved in the study. The mean age of the respondents was $41.76( \pm 9.00)$ years and $40.20 \%$ were in the age range of 41 to 50 years. Out of the total respondents, $64.3 \%$ were male, $35.4 \%$ were protestant Christian, $43.2 \%$ had attended secondary and above education, $64 \%$ were married, and $71.4 \%$ of respondents were urban residents (Table 1). 
Table 1 Socio-demographic characteristics of the respondents MTUTH and TGH southwest Ethiopia, July 2018

\begin{tabular}{|c|c|c|c|}
\hline Variables & Categories & Frequency & Percent \\
\hline \multirow[t]{4}{*}{$\overline{\text { Age }}$} & $18-30$ & 54 & 13.6 \\
\hline & $31-40$ & 117 & 29.4 \\
\hline & $41-50$ & 160 & 40.2 \\
\hline & $51+$ & 67 & 16.8 \\
\hline \multirow[t]{2}{*}{ Sex } & Male & 256 & 64.3 \\
\hline & Female & 142 & 35.7 \\
\hline \multirow[t]{4}{*}{ Religion } & Orthodox & 136 & 34.2 \\
\hline & Protestants & 141 & 35.4 \\
\hline & Muslim & 96 & 24.1 \\
\hline & Others & 25 & 6.3 \\
\hline \multirow[t]{3}{*}{ Marital status } & Married & 263 & 66.1 \\
\hline & Single & 49 & 12.3 \\
\hline & Divorced /widowed & 86 & 21.6 \\
\hline \multirow[t]{5}{*}{ Ethnicity } & Kaficho & 106 & 26.6 \\
\hline & Amhara & 101 & 25.4 \\
\hline & Bench & 60 & 15.1 \\
\hline & Shakacho & 50 & 12.6 \\
\hline & Others & 80 & 20.1 \\
\hline \multirow[t]{3}{*}{ Educational status } & No education & 106 & 26.6 \\
\hline & Primary & 120 & 30.2 \\
\hline & Secondary and above & 172 & 43.2 \\
\hline \multirow[t]{2}{*}{ Residence } & Urban & 284 & 71.4 \\
\hline & Rural & 114 & 28.6 \\
\hline
\end{tabular}

\section{Behavioral and medical-related factors}

Nearly two-thirds (67.6\%) of study participants were engaged in moderate to vigorous physical activity. One hundred fifty-eight (39.7\%) respondents had history of substance use in the past 12 months. The substance commonly used was alcohol (20.9\%). Seventy-four percent of the respondents adhered to antidiabetic medication in the past 7 days before the interview (Table 2). Out of 398 respondents, 318 (79.9\%) were Type 2 Diabetes Mellitus (T2DM) patients. Based on the American

Table 2 Behavioral related factors of respondents, MTUTH and TGH southwest Ethiopia, July $2018(n=398)$

\begin{tabular}{llll}
\hline Variables & Categories & Frequency & Percent \\
\hline Physical exercise & Yes & 269 & 67.6 \\
Substance use & Yes & 158 & 39.7 \\
Adherence to anti-diabetic & Adherent & 293 & 73.6 \\
medication & Not Adherent & 105 & 24.4 \\
Alcohol & Yes & 83 & 20.9 \\
Khat & Yes & 54 & 13.8 \\
Tobacco & Yes & 35 & 9 \\
\hline
\end{tabular}

Diabetic Association (ADA) guideline recommendation, $87.9 \%$ of the patients were in poor control glycaemic range (FBS $>130 \mathrm{mg} / \mathrm{dL}$ ). The prevalence of depression among study participants was 36.9\% (Table 3). Moreover, $39 \%$ of patients were experienced complications related to DM and the common complication was hypertension (24.3\%) (Fig. 1).

\section{Prevalence of sexual dysfunction}

The prevalence of global sexual dysfunction among study participants was 53.3\% (95\% CI: 48.35-58.25\%). Gender wise, the prevalence of global sexual dysfunction was 52\% (95\% CI: 46-58\%) among males and 56.6\% (95\% CI: 47-64\%) among females. The most prevalent dysfunction among men was frequency of sexual desire disorder (60.9\%) followed by orgasmic dysfunction (56.6\%). Among women, frequency of sexual desire disorder was the most common sexual dysfunction (46.5\%), followed by desire (interest) dysfunction (36.6\%) (Fig. 2).

\section{Factors associated with sexual dysfunction}

In bivariate binary logistic regression analyses, age, marital status, educational status, physical activity, substance use, adherence to anti-DM medication, type of DM, duration of treatment, complication of DM or comorbidity and presence of depression had a $p$-value of $\leq 0.25$; hence, they were candidates for a multivariable model. However, sex, religion, ethnicity, and duration of treatment were not significant at $p$-value of $\leq 0.25$; therefore, they were excluded from multivariable analysis. In the multivariable binary logistic model, age of respondents, educational status, marital status, types of diabetes mellitus, complication or comorbidity, the presence of depression and physical activity were significantly associated $(p<0.05)$ with sexual dysfunction.

Table 3 Medical condition of the respondents, MTUTH and TGH Southwest Ethiopia, July $2018(n=398)$

\begin{tabular}{llll}
\hline Variables & Categories & Frequency & Percent \\
\hline Type of DM & T1DM & 80 & 20.1 \\
& T2DM & 318 & 79.9 \\
Duration of treatment & $<5$ years & 299 & 75.1 \\
& $>=5$ years & 99 & 24.9 \\
Glycemic control & Poor & 350 & 87.9 \\
& Good & 48 & 12.1 \\
Complication or co-morbidity & Yes & 212 & 53.3 \\
& No & 186 & 46.7 \\
Depression & Yes & 147 & 36.9 \\
& No & 251 & 63.1 \\
\hline
\end{tabular}

Poor: FBS > $130 \mathrm{mg} / \mathrm{dL}$, Good: FBS $\leq 130 \mathrm{mg} / \mathrm{dL}$

Complication or co-morbidity (nephropathy, retinopathy, diabetic neuropathy, diabetic foot ulcer, cardiac disease and/or hypertension) 


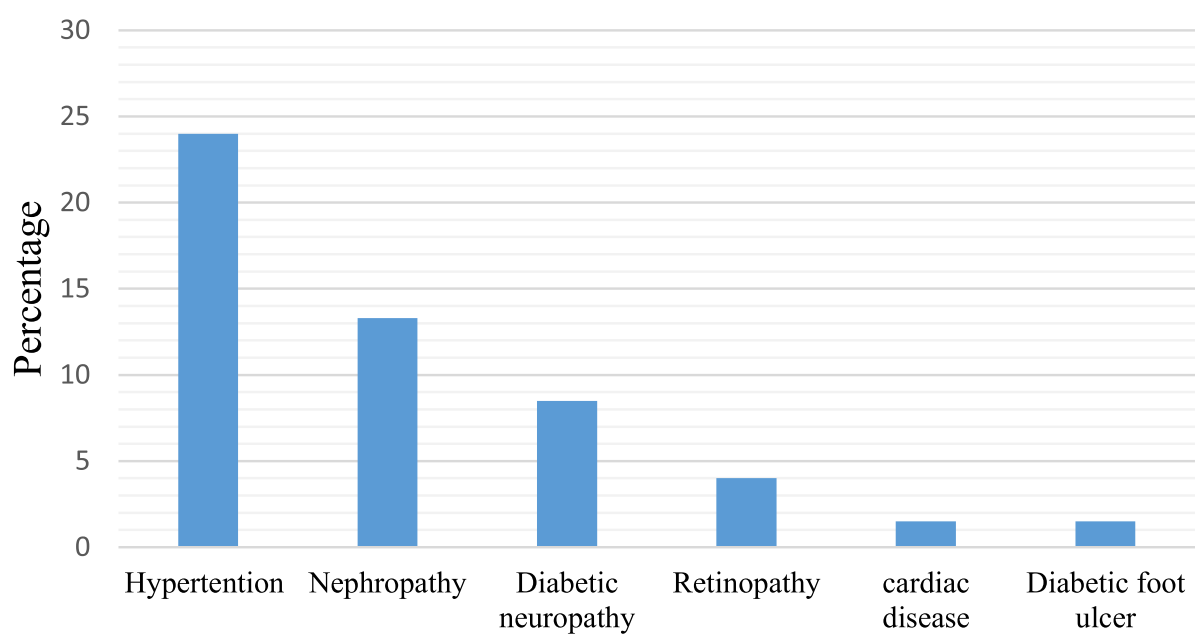

DM related complications or co-morbidities

Fig. 1 DM-related complications among respondents, MTUTH and Tepi- General Hospital southwest Ethiopia July $2018(n=398)$

Based on adjusted odds ratio, DM patients in the age range of above 41 years had 3.98 times higher odds of sexual dysfunction as compared to those in the age range of less than or equal to 41 years $(\mathrm{AOR}=3.98 ; 95 \%$ CI: 2.32-6.85). The odds of sexual dysfunction was 3.2 times higher for patients who did not attend education in reference to those who attended secondary school or above education (AOR $=3.20$; 95\% CI: 2.32-6.85). However, there was no statistically significant difference in odds of sexual dysfunction between patients who attended and secondary school or above $(\mathrm{AOR}=0.46$;
95\%:0.20-1.00). Participants who did not involve in physical activity had 1.62 (AOR $=1.62$; 95\% CI: $1.47-$ 1.77) times higher odds of sexual dysfunction than the counterpart. With reference to Type 1 Diabetes Miletus (T1DM), the odds of sexual dysfunction among T2DM patients were 4.52 times higher $(\mathrm{AOR}=4.52$ : $95 \% \mathrm{CI}$ : 2.17-9.42). The sexual dysfunction among patients who had complication or comorbidity was 2.05 times $(\mathrm{AOR}=$ 2.05; 95\% CI: 1.18-3.58) higher when compared to those who didn't have such history. The odds of sexual dysfunction was 4 times higher for diabetic patients who

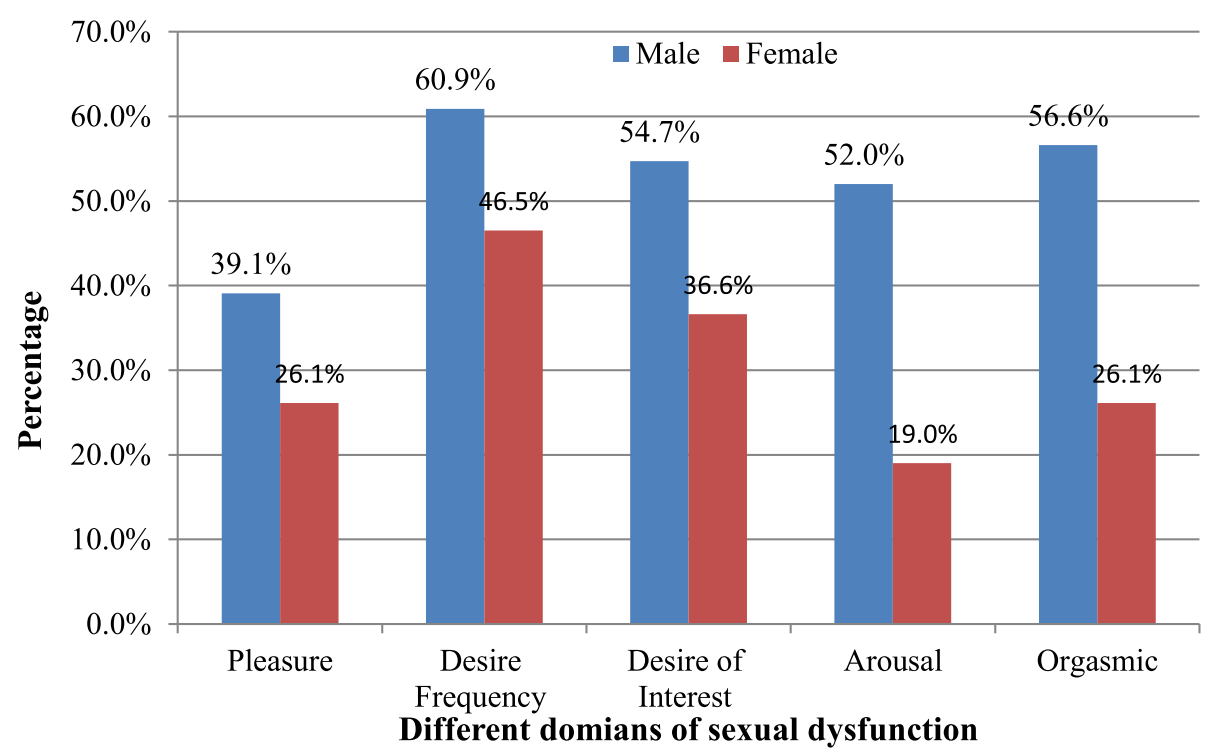

Fig. 2 Prevalence of different domain of sexual dysfunction among male and female, MTUTH and Tepi General Hospital southwest Ethiopia, July 2018 (Males $=256$, Females $=142$ ) 
had symptoms of depression as compared to those who had no depression (AOR $=4.05 ; 95 \%$ CI: 2.32-7.10) (Table 4).

\section{Discussion}

The study revealed that the prevalence of sexual dysfunction among diabetes mellitus patients was 53.3\%. This magnitude is similar to the study conducted among diabetic patients in Tanzania [17]. Other studies also reported high prevalence of sexual dysfunction among DM patients $[18,19]$. But, this finding is lower compared with the study done in Iran [20], Tigray [21] and Felege Hiwot Referral Hospital, Northern Ethiopia [13]. This variation might be due to differences in the sociocultural related factors of study participants and the tool used to measure sexual dysfunction in different studies. For instance, the studies conducted in Tigray and Felege Hiwot Referral Hospital used the International Index of Erectile Function (IIEF), and the study conducted in Iran used IIEF and Female Sexual Function Index (FSFI). The high prevalence of sexual disorders amongst DM patients could be due to prolonged hyperglycemia that causes impairment of sexual functions by causing atherosclerosis, diabetic neuropathy, diabetes-induced endothelial dysfunction and endocrinological changes $[19,22]$. Yet, the high prevalence of sexual dysfunction in this study might be due to lack of control for some medical, psychological and drug-related factors that can affect sexual function.

In this study higher age were associated with increased odds of sexual dysfunction in DM patients. A similar finding was published by a study conducted at Felege Hiwot Referral Hospital [13]. Furthermore, the finding of this study is consistent with a report from other similar studies $[17,20]$. The increased risk of sexual dysfunction at older age, might be due to advanced age is correlated with long duration of treatment, increased DM related complications and/or other co-morbidities, poor glycemic control, change in hormonal function and BMI which can affect sexual function.

Similar to a report from another study [23], patients who did not attend education had a higher risk of having sexual dysfunction. This might be due to uneducated people had limited get access to health information; hence, they may not adhere to behaviors that delay or prevent DM complications. Besides, they may unaware of the disorder and its treatment; thus, they may not seek treatment for it. Moreover, this might be due to not attending education in most of the case associated with unemployment and financial insecurities that can result in inability to pay for medical cost, and having poorer nutritional choices, which can cause poor glycemic control and finally leads to sexual dysfunction or other complications.

In this study, participants who were widowed or divorced had a higher risk of sexual dysfunction when compared to those in the marital union. This finding is supported by a study done at Amanuel Mental Specialized Hospital [24]. This might be due to individuals in the marital union can get positive benefits such as high social and psychological support that improve adherence to antidiabetic medications. This, in turn, leads to good

Table 4 Factors associated with sexual dysfunction among respondents, MTUTH and TGH Southwest Ethiopia July, 2018

\begin{tabular}{|c|c|c|c|c|c|c|}
\hline \multirow[t]{2}{*}{ Variables } & \multirow[t]{2}{*}{ Categories } & \multicolumn{2}{|c|}{ Sexual dysfunction } & \multirow[t]{2}{*}{ COR $(95 \% \mathrm{Cl})$} & \multirow[t]{2}{*}{ AOR $(95 \% \mathrm{Cl})$} & \multirow{2}{*}{$\begin{array}{l}P \text { - } \\
\text { value }\end{array}$} \\
\hline & & Yes (\%) & No (\%) & & & \\
\hline \multirow[t]{2}{*}{ Age group } & $<=41$ & $70(38)$ & $144(62)$ & 1 & 1 & \\
\hline & $>41$ & $142(66.4)$ & 72(33.6) & $3.21(2.13-4.85)$ & $3.98(2.32-6.85)$ & 0.00 \\
\hline \multirow[t]{3}{*}{ Educational status } & No education & $60(56.6)$ & $46(43.4)$ & $3.81(2.31-6.27)$ & $3.20(1.60-6.39)$ & 0.00 \\
\hline & Primary & $85(70.8)$ & $35(29.2)$ & $2.04(1.25-3.34)$ & $0.46(0.20-1.00)$ & 0.318 \\
\hline & Secondary and above & $67(39)$ & $105(61)$ & 1 & 1 & \\
\hline \multirow[t]{2}{*}{ Exercise } & Yes & $130(48.3)$ & 139(51.7) & 1 & 1 & \\
\hline & No & $82(63.6)$ & $47(36.4)$ & $1.87(1.21-2.87)$ & $1.62(1.47-1.77)$ & 0.037 \\
\hline \multirow[t]{3}{*}{ Marital status } & Married & $114(43.3)$ & 149(56.7) & 1 & 1 & 0.007 \\
\hline & Single & $25(51)$ & 24(49) & $1.36(0.74-2.50)$ & $1.59(0.67-3.78)$ & 0.78 \\
\hline & Divorced and widowed & $73(84.9)$ & 13(15.1) & 7.34(3.88-13.89) & $5.28(2.35-11.86)$ & 0.02 \\
\hline \multirow[t]{2}{*}{ Types of DM } & T1DM & 25(31.3) & $55(68.8)$ & 1 & 1 & \\
\hline & T2DM & 187(58.8) & $131(41.2)$ & $3.14(1.86-5.30)$ & $4.52(2.17-9.42)$ & 0.00 \\
\hline \multirow[t]{2}{*}{ Complication/co-morbidity } & Yes & $97(62.2)$ & $115(47.5)$ & $1.82(1.21-2.74)$ & $2.05(1.18-3.58)$ & 0.01 \\
\hline & No & $59(37.8)$ & $127(52.5)$ & 1 & 1 & \\
\hline \multirow[t]{2}{*}{ Depression } & Yes & $102(69.4)$ & $45(3.6)$ & $2.91(1.89-4.67)$ & $4.05(2.32-7.10)$ & 0.00 \\
\hline & No & $110(43.8)$ & $141(56.2)$ & 1 & 1 & \\
\hline
\end{tabular}


treatment response, and delay complications of DM. In addition, divorced or widowed individuals probably have decreased frequency of sexual desire due to the loss of their beloved partner. On the other hand, sexual dysfunction itself imposes a challenge on partner relationships and might result in divorce.

The study also reveals that patients with T2DM were at an increased risk of experiencing SD compared to patients with T1DM. This finding is in line with a study conducted in Iran and Tanzania [20, 25]. Also, the finding is consistent with reports from other studies $[6,26]$. Diabetic patients who had complication or co-morbidity were twice more likely to have sexual dysfunction when compared to those who did not have complication or co-morbidity. The finding is consistent with reports from different similar studies [7, 27-30]. This could be due to complication related to DM and co-morbidity can contribute to the pathogenesis of sexual dysfunctions. For instance, endocrine-related complication can lead to hypogonadism. Another study reported that sexual dysfunction is a marker for the development of chronic conditions such as DM and coronary artery disease [29]. These findings suggest that diabetic complications may play an important role in decreasing sexual function, and hence prevention of diabetic complications may be help to prevent sexual dysfunction in a patient with diabetes.

The study indicated a strong association between sexual dysfunction and depression. This result is supported by a study done in Iran [24]. Likewise, other studies also revealed an increased risk of sexual disorders among diabetic patients with depressive symptoms [31, 32]. On the other way, a study also showed an increased risk of depression among patients with chronic diseases [33]. A meta-analysis also confirmed a bidirectional association between depression and sexual dysfunctions [34].

In this study, adherence to exercise was associated with decreased risk of sexual dysfunction among DM patients. This is in line with a study conducted in Ghana [35]. Similarly, another study showed that physical activity is a significant predictor of erectile dysfunction [36]. This could be due to exercise is a key aspect of a healthy lifestyle that might benefit DM patients to prevent high blood glucose levels and DM-related complications. Additionally, exercise enhances sexual satisfaction indirectly through restoring autonomic nerve flexibility which in turn helps to improve cardiovascular health and mood [37].

\section{Limitation}

The study addressed the issue that was not well studied in Ethiopia. However, due to the cross-sectional nature of our study, we cannot be sure of the temporal relationship between different factors and sexual dysfunction.
Furthermore, the study was done on a culturally sensitive and embarrassing issue, therefore, social desirability bias could not be ruled out. As a result, patients may under-report the problem. In addition, since the study was conducted among patients in hospitals, the finding may not represent patients on follow-up in other settings.

\section{Conclusion}

The prevalence of sexual dysfunction was as high as reports from other studies. Therefore, health care providers should include the issue of sexual health in their routine discussions with diabetes patients. Presence of depression, not doing physical activity and DM complication and/or comorbidity are modifiable factors associated with sexual dysfunction; therefore, they should be attended during care addressing sexual dysfunction.

\section{Abbreviations}

ADA: American Diabetic Association; AOR: Adjusted Odds Ratio; CO: Crude Odd Ratio; CSFQ: Change in Sexual Functioning Questionnaire; DM: Diabetes Mellitus; MTUTH: Mizan Tepi University Teaching Hospital; PHQ: Patient Health Questionnaire; SD: Sexual Dysfunction; T1DM: Type 1 Diabetes mellitus; T2DM: Type 2 Diabetes mellitus; TGH: Tepi General Hospital; WHO: World Health Organization

\section{Acknowledgments}

We are extremely grateful to Mizan-Tepi University for the arrangement of a conducive platform to undertake research. We extend our thanks to the study participants and data collectors.

\section{Authors' contributions}

$\mathrm{AA}, \mathrm{TN}, \mathrm{AH}$, and $\mathrm{YM}$ conceived and designed the study. All authors participated in data analysis. AA and YM drafted a first manuscript, which was then edited by all other authors. All authors read and approved the final manuscript.

\section{Funding}

No formal funder.

\section{Availability of data and materials}

The datasets used and analyzed during the current study are available from the corresponding author on reasonable request.

Ethics approval and consent to participate Ethical clearance was obtained from the Institutional Review Board (IRB) of Mizan-Tepi University. Also, informed written consent was obtained from all participants after explaining the purpose of the study, importance of their contribution as well as the right to refuse participation. All the information gathered was kept confidential.

Consent for publication

Not applicable.

Competing interests

All authors declare that they have no competing interest.

\section{Author details}

${ }^{1}$ Department of Public Health, College of Health Science, Mizan- Tepi University, Mizan-Aman, Ethiopia. ${ }^{2}$ Department of Pharmacy, College of Health Science, Mizan- Tepi University, Mizan-Aman, Ethiopia. 
Received: 1 May 2019 Accepted: 10 December 2019

Published online: 18 December 2019

\section{References}

1. World Health Organization. Global report on diabetes [Internet]. 2016. Available from: https://apps.who.int/iris/bitstream/handle/10665/204874/ WHO_NMH_NVI_16.3_eng.pdf?sequence $=1$

2. Ogurtsova K, Rocha JD, Huang Y, Linnenkamp U, Guariguata L. IDF diabetes atlas : global estimates for the prevalence of diabetes for 2015 and 2040 Diab Res Clin Pract [Internet]. 2017;128:40-50. https://doi.org/10.1016/j. diabres.2017.03.024

3. Maiorino MI, Bellastella G, Esposito K. Diabetes and sexual dysfunction: current perspectives. Diab Metab Syndr Obes Targets Ther. 2014;7:95-105.

4. National Institute of Diabetes and Digestive and Kidney Diseases. Sexual and Urologic Problems of Diabetes. 2012; Available from: http://diabetes. niddk.nih.gov/dm/pubs/sup/

5. Várkonyi T, Kempler P. Sexual dysfunction in diabetes. Handb Clin Neurol [Internet] 2014;126:223-232. Available from: http://www.ncbi.nlm.nih.gov/ pubmed/25410225\%5Cnhttp://linkinghub.elsevier.com/retrieve/pii/ B9780444534804000175

6. Seid A, Gerensea H, Tarko S, Zenebe Y, Mezemir R. Prevalence and determinants of erectile dysfunction among diabetic patients attending in hospitals of central and northwestern zone of Tigray, northern Ethiopia: a cross-sectional study. BMC Endocr Disord [Internet]. 2017;17(1):16. Available from: http://www.ncbi.nlm.nih.gov/pubmed/28298205\%0Ahttp://www pubmedcentral.nih.gov/articlerender.fcgi?artid=PMC5353861\%0Ahttp:// bmcendocrdisord.biomedcentral.com/articles/10.1186/s12902-017-0167-5.

7. Arrellano-Valdez F, Urrutia-Osorio M, Arroyo C, Soto-Vega E. A comprehensive review of urologic complications in patients with diabetes. Springerplus. 2014;3:549.

8. Nelson C. The impact of male sexual dysfunction on the female partner. Curr Sex Heal Reports. 2006;3(1):37.

9. Kate M, Peter R, Geoffrey I. Association of sexual problems with social, psychological, and physical problems in men and women: a cross-sectional population survey. J Epidemiol Commun Heal. 1999:53:144-8.

10. Berg-Cross L. Sexuality and the Couple Relationship. In: Berg-Cross L, editor. Couples Therapy. N Y: Press THCP; 2001. p. 357-62.

11. Access O. Sexual Satisfaction in Patients with Diabetes Type 2 and Their Partners. Int J Psychol Behav Anal. 2016;2:1-6.

12. Klausner E, Koenigsberg $H$, Skolnick N, Chung H, Rosnick $P$, et al. Perceived familial criticism and glucose control in insulindependent diabetes mellitus. Int J Ment Heal. 1995;24:64-75.

13. Walle B, Lebeta KR, Fita YD, Abdissa HG. Prevalence of erectile dysfunction and associated factors among diabetic men attending the diabetic clinic at Felege Hiwot Referral Hospital , Bahir Dar, North West Ethiopia, 2016. BMC Res Notes [Internet]. 2018;11:130. Available from: https://doi.org/https://doi. org/10.1186/s13104-018-3211-2

14. Daniel W. A foundation for analysis in the health science. 7th ed. Willey: Yew York; 1999

15. Anita C, Elizabeth M, Gail C. The change in sexual fuctioning questionnaire (CSFQ): development reliability and validity. Psychopharmacol Bull. 1997 33(4):731-45.

16. Udedi M, Muula AS, Stewart RC, Pence BW. The validity of the patient health Questionnaire-9 to screen for depression in patients with type-2 diabetes mellitus in non-communicable diseases clinics in Malawi. BMC Psychiatry. 2019;18:81.

17. Seftel AD. Prevalence of erectile dysfunction and associated factors among diabetic men attending the diabetic clinic at Muhimbili National Hospital in Dar-es-salaam. Tanzan J Urol. 2015;193(4):1325-6.

18. Wessells H, Braffett BH, Holt SK, Jacobson AM, Kusek JW, Cowie C, et al. Burden of urological ComplicationsinMenandWomen with long-standing type 1 diabetes in the diabetes control and complications trial/ epidemiology of diabetes interventions and complications cohort. Diab Care. 2018;41(10):2170-7

19. Meade CRL. A practical approach to managing hypoactive sexual desire disorder in women with diabetes. Diab Ther. 2017;8(5):991-8.

20. Ziaei-Rad M, Vahdaninia M, Montazeri A. Sexual dysfunctions in patients with diabetes: a study from Iran. Reprod Biol Endocrinol [Internet]. 2010;8(1): 50. Available from: http://rbej.biomedcentral.com/articles/https://doi.org/10. 1186/1477-7827-8-50.
21. Seid A, Gerensea H, Tarko S, Zenebe Y, Mezemir R. Prevalence and determinants of erectile dysfunction among diabetic patients attending in hospitals of central and northwestern zone of Ti. 2017;(March).

22. Clayton A. The pathophysiology of hypoactive sexual desire disorder in women. Int J Gynaecol Obstet. 2010;110:7-11.

23. Annani-akollor ME, Addai-mensah O, Fondjo LA, Sallah L, Owiredu E, Acheampong $\mathrm{E}$, et al. Predominant Complications of Type 2 Diabetes in Kumasi : A 4-Year Retrospective Cross-Sectional Study at a Teaching Hospital in Ghana. Medicina (B Aires). 2019:55:125.

24. Fanta T, Haile K, Abebaw D, Assefa D, Hibdye G. Assessment of sexual dysfunction and associated factors among patients with schizophrenia in Ethiopia, 2017. BMC Psychiatry. 2018;18:158.

25. Mutagaywa RK, Lutale J, Aboud M, Kamala BA. Prevalence of erectile dysfunction and associated factors among diabetic men attending diabetic clinic at Muhimbili National Hospital in Dar-es-salaam. Tanzan PanAfrica Med J. 2014;8688:1-8

26. Nowosielski K, Drosdzol A, Sipiński A, Kowalczyk R, Skrzypulec V. Diabetes mellitus and sexuality - does it really matter? J Sex Med. 7(2 Pt 1):723-35.

27. Ugwu T. Predictors of erectile dysfunction in men with type 2 diabetes mellitus referred to a tertiary healthcare Centre. Adv Endocrinol. 2016:1-8.

28. Constance G, Frank B, Edward G, Dale B, Murray A, Eric B. Association of Type and Duration of diabetes with erectile dysfunction in a large cohort of men. Diab Care. 2002;25:1458-63.

29. Hackett G. Erectile dysfunction, diabetes and cardiovascular risk. Br J Diab. 2016;16(2):52-7.

30. Ezeani I, Onyeonoro U, Ugwu E. Evaluation of Female Sexual Function in Persons With Type 2 Diabetes Mellitus Seen in a Tertiary Hospital in Southeast Nigeria With Emphasis on its Frequency and Predictors. J Sex Marital Ther [Internet]. 2019; Available from: https://doi.org/10.1080/ $0092623 \times .2019 .1654583$

31. Corona G, Rastrelli G, Ricca V, Jannini E, Vignozzi L, Monami M, et al. Risk factors associated with primary and secondary reduced libido in male patients with sexual dysfunction. J Sex Med. 2013:10:1074-89.

32. Bąk E, Marcisz C, Krzemińska S, Dobrzyn-Matusiak D, Foltyn A, Drosdzol-Cop A. Relationships of Sexual Dysfunction with Depression and Acceptance of Illness in Women and Men with Type 2 Diabetes Mellitus. Int J Environ Res Public Health [Internet]. 2017;14(9) Available from: http://www.ncbi.nlm.nih. gov/pubmed/28926936. [cited 2019 Aug 20].

33. Katon W. Clinical and health services relationships between major depression, depressive symptoms, and general medical illness. J Bio Psychiatry. 2003;54(3):216-26.

34. Atlantis $\mathrm{E}$, Sullivan T. Bidirectional association between depression and sexual dysfunction: a systematic review and meta-analysis. J Sex Med. 2012; 9:1497-507.

35. Owiredu WK, Amidu N, Alidu H, Sarpong C, Gyasi-Sarpong CK. Determinants of sexual dysfunction among clinically diagnosed diabetic patients. Reprod Biol Endocrinol [Internet]. 2011;9(1):70. Available from: http://rbej. biomedcentral.com/articles/https://doi.org/10.1186/1477-7827-9-70.

36. Mark R, Huri HZ, Hassan A, Razack A. Demographic, clinical and lifestyle predictors for severity of erectile dysfunction and biomarkers level in Malaysian patients. Braz J Pharm Sci. 2014;54(3):e17552.

37. Stanton M, Handy A, Meston C. The effect of exercise on sexual function in women. Sex Med Rev. 2018:6:548-57.

\section{Publisher's Note}

Springer Nature remains neutral with regard to jurisdictional claims in published maps and institutional affiliations.

Ready to submit your research? Choose BMC and benefit from:

- fast, convenient online submission

- thorough peer review by experienced researchers in your field

- rapid publication on acceptance

- support for research data, including large and complex data types

- gold Open Access which fosters wider collaboration and increased citations

- maximum visibility for your research: over $100 \mathrm{M}$ website views per year

At $\mathrm{BMC}$, research is always in progress.

Learn more biomedcentral.com/submission 